\title{
Retroperitoneal Cellular Schwannoma: Report of a Case Diagnosed by the Presence of S-100 Protein
}

\author{
Koji YAmAMOTO, Jun-ichiro MiYagAwa, Hayato KATSURA, Naoto ITOH, \\ Toshiaki HanAfuSA, Tsutomu KASUGAI*, Koh TOKUNAGA**, Masakazu MORI***, \\ Norio KONO, Kaname MORIWAKI, Seiichiro TARUI
}

\begin{abstract}
A case of cellular schwannoma originating from the retroperitoneum is reported. The histological features of the tumor resembled those of a smooth muscle tumor. However, the tumor cells were positive for S-100 protein, which is almost exclusively identified within nerve sheath tumor cells. This finding confirmed the diagnosis of cellular schwannoma. This type of tumor is generally considered to be benign but is sometimes mistaken for a malignant tumor. These findings indicate that it is important to prove whether or not S-100 protein is present in the cells of a tumor of unknown origin especially arising in the mediastinum or retroperitoneum.
\end{abstract}

Key words: Diagnosis, Immunocytochemistry, Nerve sheath tumor

Schwannoma is a tumor of the peripheral nerve, and it is considered to be relatively rare and benign. The most frequent site of origin is the head and neck region. Morphologically, two patterns of tissues have been described. One is the Antoni A pattern which shows compactly aggregated long bipolar spindle cells, forming a palisading arrangement of cells with their nuclei referred to as Verocay bodies. The other is the Antoni B pattern distinguished by loose areas in which tumor cells are widely spaced.

Cellular schwannoma, characterized by its high cellularity in spite of lacking either nuclear palisading or Verocay bodies was first defined as a distinct and benign type of schwannoma by Woodruff et al (1). Histological findings of the cellular schwannoma resemble those of a smooth muscle tumor or fibrous histiocytoma, and the tumor is sometimes mistaken for a malignant tumor. In this report, a case of retroperitoneal cellular schwannoma is presented, which was diagnosed immunocytochemically by the existence of S-100 protein which is specifically present in the nerve sheath.

\section{CASE REPORT}

A 37-year-old woman was admitted to Osaka University Hospital on October 26, 1988. Her chief complaint was right back pain. Both the past history and family history were unremarkable. She had a record of lumbago and abdominal pain in 1982; however no physical abnormality was detected by an examination at Kawanishi Municipal Hospital (Hyogo prefecture). The right back pain was first noticed in October 1988. When she consulted the hospital, a right peritoneal mass in contact with the upper portion of the right kidney was detected by abdominal CT scan. Because an adrenal tumor was suspected, the patient was admitted to our hospital.

On physical examination, a hard, immobile and oval mass (about $7 \times 4 \mathrm{~cm}$ ) was palpable on the right upper abdomen. The mass was slightly tender on palpation. There was no other physical abnormality. Complete blood counts revealed slight anemia (RBC

From Second Department of Internal Medicine, Departments of *Pathology, **Radiology, Osaka University Medical School, Osaka, and ***Kawanishi Municipal Hospital, Kawanishi

Received for publication May 23, 1990; Accepted for publication February 5, 1991

Reprint requests should be addressed to Koji Yamamoto, MD, Second Department of Internal Medicine, Osaka University Medical School, Fukushima-ku, Osaka 553, Japan 
$\left.3.84 \times 10^{12} / 1, \quad \mathrm{Hb} 116 \mathrm{~g} / \mathrm{l}\right)$ and thrombocytosis $\left(472 \times 10^{9} / 1\right)$, while the white blood cell count was within normal limits. Erythrocyte sedimentation rate was markedly increased $(114 \mathrm{~mm} / \mathrm{h})$. The liver and renal functions were within normal limits, but total cholesterol was $3.88 \mathrm{mmol} / 1$ (normal range: 4.14 $5.43 \mathrm{mmol} / \mathrm{l})$. Serum globulin content was $34 \mathrm{~g} / \mathrm{l}$ (N: 20-30 g/l). Serum Fe was $10 \mu \mathrm{mol} / 1$ (N: $18-21$ $\mu \mathrm{mol} / \mathrm{l})$, while $\mathrm{Cu}$ was $28.3 \mu \mathrm{mol} / \mathrm{l}$ (N: $12.2-20.5$ $\mu \mathrm{mol} / \mathrm{l}$ ), ceruloplasmin was $490 \mathrm{mg} / \mathrm{l}$ (N: $170-370$ $\mathrm{mg} / \mathrm{l})$, haptoglobin was $4.25 \mathrm{~g} / 1(\mathrm{~N}: 0.42-3.00 \mathrm{~g} / \mathrm{l})$, and plasma fibrinogen was $4.84 \mathrm{~g} / \mathrm{l}(\mathrm{N}: 1.80-3.50$ $\mathrm{g} / \mathrm{l})$. C-reactive protein was $41 \mathrm{mg} / \mathrm{l}(\mathrm{N}:<2 \mathrm{mg} / \mathrm{l})$. These abnormalities were suggestive of the presence of a malignant tumor or chronic inflammation.

The basal levels of pituitary and adrenocortical hormones such as adrenocorticotropic hormone $(\mathrm{ACTH})$, cortisol and aldosterone, as well as adrenomedullary hormones such as plasma catecholamines, were within normal limits. Plasma cortisol and aldosterone showed normal responses in rapid ACTH test. From these results, the diagnosis of a functioning adrenal tumor was excluded. As for tumor markers, $\alpha$-fetoprotein (AFP), carcinoembryonic antigen (CEA), neuron specific enolase (NSE), CA19-9, ferritin, and $\beta_{2}$-microglobulin were all within normal limits, but immunosuppressive acidic protein (IAP) was 1,199 $\mathrm{ng} / \mathrm{ml}(\mathrm{N}:<500 \mathrm{ng} / \mathrm{ml})$. The examination of urinary sediments and bone marrow puncture showed no abnormalities.

Abdominal CT scan revealed a large mass $(90 \times 87 \mathrm{~mm})$ medial to the right kidney, encasing the inferior vena cava and entrapping the right renal artery (Fig. 1). Abdominal aortography demonstrated a mass not supplied by the adrenal artery, but mainly supplied by the dorsal pancreatic artery (Fig. 2). The dorsal pancreatic artery was confirmed as a main feeder during fluoroscopical examination. These findings indicated that the mass did not originate from the adrenal gland, although the precise origin of the tumor could not be confirmed.

Autopsy was performed by permission of the patient's family after her sudden death due to massive pulmonary embolism on the 23rd hospital day. Macroscopically, the solid tumor, $9 \mathrm{~cm}$ in diameter, with a fibrous capsule was adhering to the

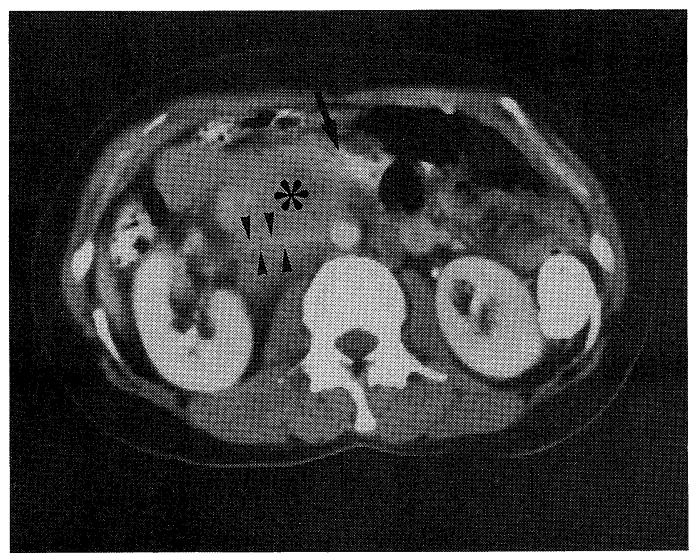

Fig. 1. Abdominal CT scan of the patient. A tumor (*) is encasing the inferior vena cava (arrow) and entrapping the right renal artery (arrow heads).

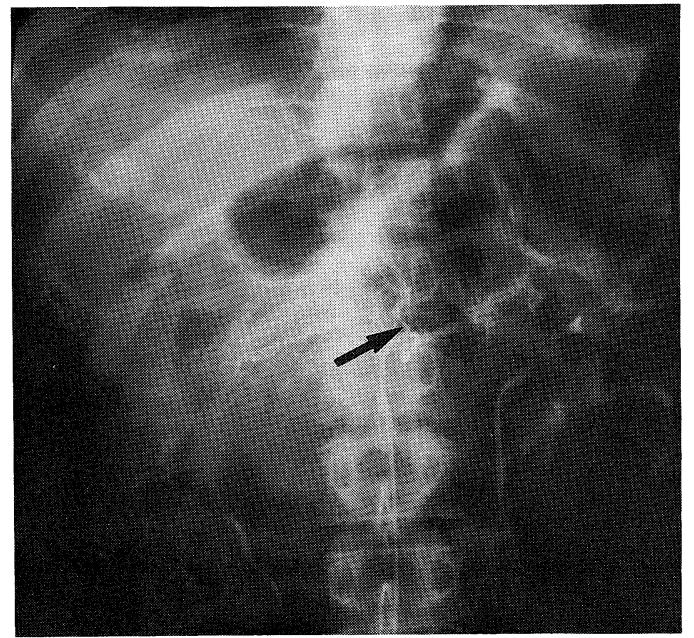

Fig. 2. A superior mesenteric angiography. Dorsal pancreatic artery (arrow) is the main feeder of the tumor.

inferior vena cava at the level of $1-9 \mathrm{~cm}$ distal to the branching portion of the right adrenal vein and was encasing a part of the right renal artery. There was no apparent local infiltration or distant metastasis of the tumor. On cross section, the central area was yellow, while the peripheral area was grey.

Microscopically, the tumor was composed of bipolar cells with spindle-like nuclei and indistinct cytoplasmic membranes. There was no apparent mitosis, and the nuclear pleomorphism was not remarkable. The tumor cells had the appearance of a smooth muscle tumor or cellular schwannoma as 
they did not show a palisading pattern which is the feature of the classical schwannoma composed of Antoni A type tissue but rather a whorled pattern (Fig. 3). Numerous lymphocytes were infiltrating into the interstitial space around vessels (Fig. 4). The immunocytochemical analysis of the subsets of infiltrating mononuclear cells exhibited that $\mathrm{T}$ lymphocytes occupied mainly the center, while B lymphocytes existed in the periphery of the infiltrate. Macrophages were also seen scattered among the tumor cells. It was considered that the macroscopically yellowish area contained much lipid and that the tumor cells in this area were foam cells (Fig. 5a). This was confirmed by positive staining of the cells for Sudan II (Fig. 5b). Although a smooth muscle tumor was suspected from these histological findings, other tumors such as cellular schwannoma could not be excluded, thus immunostaining was performed. The diagnosis of a smooth muscle tumor

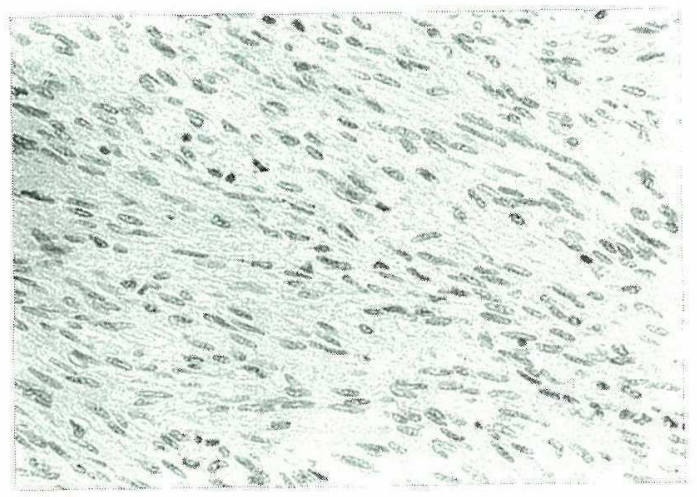

Fig. 3. The tumor tissue stained with hematoxylin and eosin. The tumor cells have spindle-like nuclei. There is no apparent mitosis or pleomorphism of nuclei $(\times 300)$.

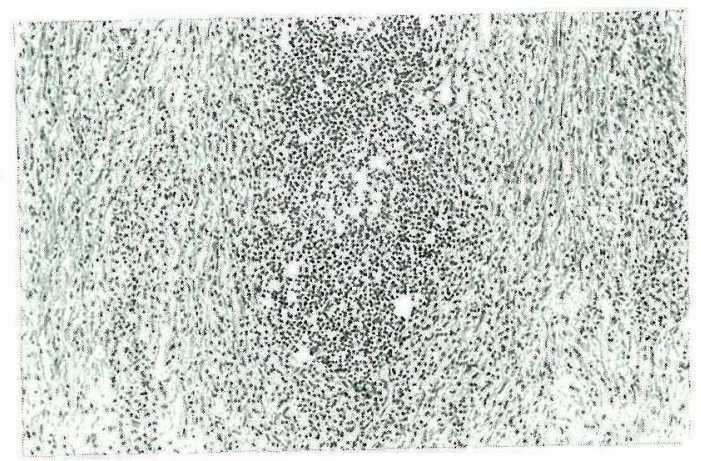

Fig. 4. The lymphocytic infiltration to the tumor tissue stained with hematoxylin and eosin $(\times 150)$. was excluded, as the tumor cells were immunocytochemically negative for desmin. Because the cells were immunocytochemically (using indirect per-

(a)
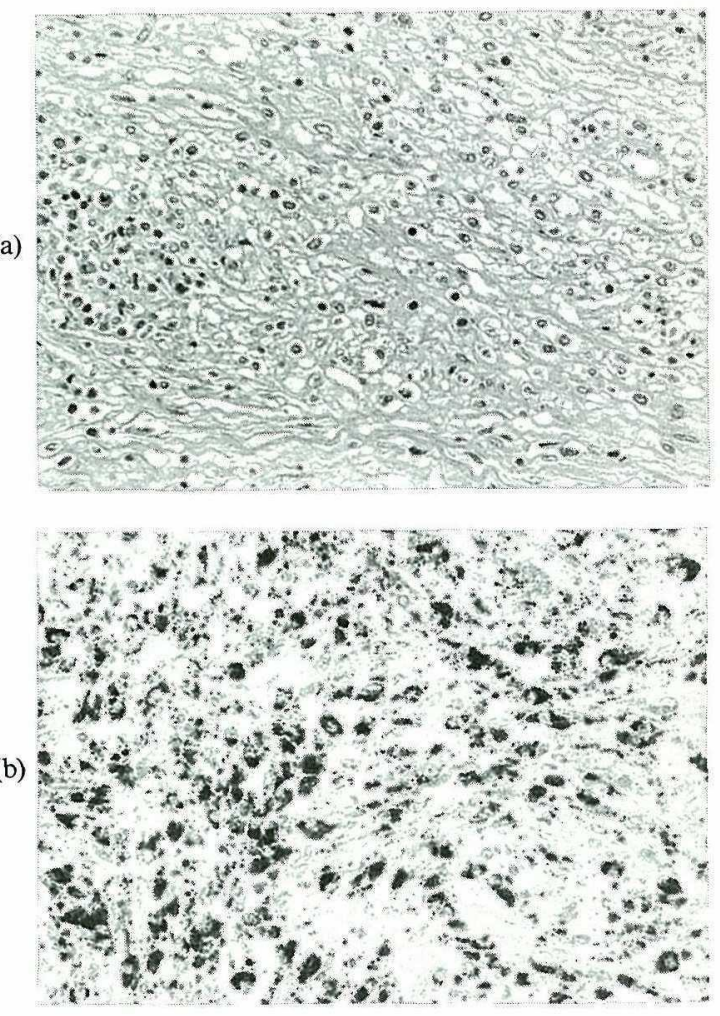

Fig. 5. (a) Foam cells in the tumor stained with hematoxylin and eosin. Cells of some areas in the center of the tumor are round or oval shaped and have a clear cytoplasm. (b) These cells are positive for lipid staining. (a: Hematoxylineosin, $\times 300$; b: Sudan II, $\times 300$ )

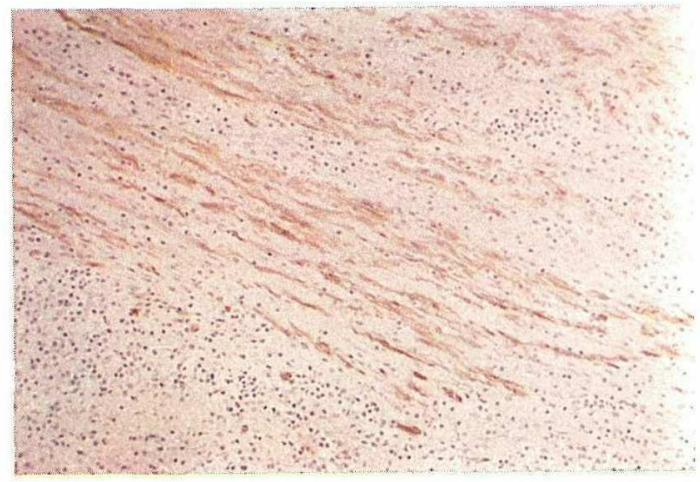

Fig. 6. Immunostaining for S-100 protein. Tumor cells show positive staining for S-100 protein. Note that the areas where lymphocytes are infiltrating are negative $(\times 150)$. 
oxidase method) positive for S-100 protein which is almost exclusively identified within benign nerve sheath tumors (Fig. 6), we diagnosed this tumor as cellular schwannoma (2).

\section{DISCUSSION}

In 1981, Woodruff et al (1) defined cellular schwannoma and reported 14 such cases. The cellular schwannoma has the following histological features, distinct from classical schwannoma: 1) lack of either nuclear palisading or Verocay bodies, in spite of high cellularity, 2) resemblance to a smooth muscle tumor or fibrous histiocytoma and 3) occasional similarity to a malignant tumor due to the presence of mitotic figures and locally destructive growth. The benign nature of cellular schwannoma was proposed by Woodruff et al (1) and Fletcher et al who reported 18 cases of cellular schwannoma followed-up for an average of $14.25 \mathrm{yr}$ (3). Conversely, Ducatman et al claimed that such lesions of the tumor represented either a low grade malignant schwannoma or anaplasia supervening in a benign schwannoma (4). In the patient described in this paper, the histological features defined by Woodruff et al except for mitotic figures or locally destructive growth were found on histological examination of the tumor.

Among benign.retroperitoneal tumors, classical schwannoma is rare $(2 / 152)$, while lipoma occurs most frequently (20/152) (5). Among classical schwannoma, the retroperitoneum is a rare site of origin (2/303), the most common being the head and neck regions (136/303) (6). However, according to the report by Fletcher et al (3) in 1987, this type of tumor originating from the retroperitoneum is not rare $(4 / 18)$. They reported that the most common site of origin of cellular schwannoma is the mediastinum $(6 / 18)$.

At first, the definite diagnosis of the present case was difficult, since the histological features such as the whorled pattern in the absence of a palisading pattern are characteristics of both a smooth muscle tumor and cellular schwannoma. The diagnosis of cellular schwannoma was confirmed only after the immunocytochemical positivity for S-100 protein of the tumor cells was demonstrated. Retrospectively, the histological findings of this case were comparable with the features of cellular schwannoma defined by Woodruff et al (1). It is considered that the nature of this tumor was benign, because mitotic activity and pleomorphism of the nuclei was not remarkable and there was neither local infiltration nor distant metastasis. This type of tumor is sometimes mistaken for a malignant tumor because of the occasional presence of mitotic figures and the patients are often given needless treatment such as irradiation or anti-cancer chemotherapy. It is thus important to demonstrate the presence or absence of immunocytochemical positivity for S-100 protein of the tumor cells to avoid unnecessary therapies.

This patient unfortunately died of massive pulmonary embolism. The reason as to why it occurred remains to be clarified but several possibilities have been considered. First, the tumor elongated the inferior vena cava, so the venous flow might have been impeded. Second, as this patient had thrombocytosis and the plasma level of fibrinogen was high, a hypercoagulability state might have existed. It is considered that thrombi could easily be formed under these conditions.

\section{REFERENCES}

1) Woodruff JM, Susin M, Godwin TA, Martini N, Erlandson RA. Cellular schwannoma. A variety of schwannoma sometimes mistaken for a malignant tumor. Am J Surg Pathol 5: 733, 1981.

2) Weiss SW, Langloss JM, Enzinger FM. Value of S-100 protein in the diagnosis of soft tissue tumors with particular reference to benign and malignant schwann cell tumors. Lab Invest 49: 299, 1983.

3) Fletcher CDM, Davis SE, Mckee PH. Cellular schwannoma: a distinct pseudosarcomatous entity. Histopathology 11: 21, 1987.

4) Ducatman BS, Scheithauer BW, Piepgras DG, Reiman HM, Ilstrup DM. Malignant peripheral nerve sheath tumors. A clinicopathological study of 120 cases. Cancer 57: 2006, 1986.

5) Scanlan DB. Primary retroperitoneal tumors. J Urol 81: 740, 1959.

6) Gupta TKD, Brasfield RD, Strong EW, Hajdu SI. Benign solitary schwannomas (neurilemomas). Cancer 24: 355, 1969. 